\title{
Impact of Strategic Human Resource Management Practices on Performance: Study on Employees in the Sri Lankan Banking Sector
}

\author{
Manthreege Wasantha Kalyani
}

\author{
University of Sri Jayewardenepura, Sri Lanka
}

\author{
Corresponding author details: Manthreege Wasantha Kalyani; Kalyani@sjp.ac.lk
}

\begin{abstract}
This work explores the effect of strategic human resource management (SHRM) activities on organizational performance, mediated by employee retention in the Sri Lankan banking sector. The data consisted of 238 workers using a selfgoverning survey and analyzed using structural equation modeling.The results suggest that the three SHRM practices of capacity enhancement, skill enhancement and motivation enhancement have a significant indirect impact on organizational performance. The relationship between SHRM activities and organizational success is often influenced by employee retention. This study provides SHRM s pecialists in the banking sector with a useful guide on which SHRM practices are significant to employee reten tion and organisational performance and hence, should be given consideration. SHRM theory has been largely developed in traditional functional manufacturing organisations but not in service-oriented organisations. This study fills the gap by examining the causal relationship between the SHRM practices and organisational performance through the mediating effect of employee retention in a service-oriented industry, i.e. the banking sector. A model that incorporates SHRM strategies is being used in the study to provide a realistic image of its relationship with employee retention and organizational performance.
\end{abstract}

Keywords: SHRM practices; organisational performance; employee retention; banking sector

Paper type: Empirical research

\section{INTRODUCTION}

HR have been perceived as the main wellspring of seriousness, since it is the human resources who utilize hierarchical resources for make intensity and to acknowledge authoritative goals. This clarifies the extensive number of calculated and exact investigations, which found that key human asset the board (SHRM) practices impact authoritative execution, for example, expanded efficiency, higher productivity and lower worker turnover rates (Knies, Boselie, Gould-Williams and Vandenabeele, 2018).

Today, most of the companies are operating in complex and dynamic environments where competition is constantly emerging. The traditional sources of competitive advantage can no longer guarantee sustainability of organisations, resulting in the need for rapid adaptation. This situation is leading to redefinition of SHRM practices and retention strategies (Pfeiffer, 1994).

Most of the studies related to SHRM practices have concentrated on the Western context, with little evidence on organisations in the Asian countries such as in the incident of the banking industry in Sri Lanka (Abewickrama, 2016; Amin, Hossain and Khatoon, 2013; Shahid, 2017). Likewise, worker maintenance has made the connection between SHRM rehearses and authoritative execution substantially more confounded as they have been recently considered. There are research confirmations to show that instead of straightforwardly impacting hierarchical execution, SHRM rehearses have been found to influence the pace of worker maintenance a good way (Antonio,
Gregorio and Arleen, 2015; Pfeiffer, 1994; Wernerfelt, 1984), addressing the 'black box' in the SHRM-performance relationship. Many researchers have echoed the need to include mediating variables in the relationship to enhance the clarity of such relationship (Alcazar, Fernandez and Gardey, 2005; Becker and Gerhart, 1996; Katou, 2008), with employee retention being one of them.

Representative maintenance is a particularly common issue among the workers in the financial area in Sri Lanka, which calls for development and implementation of effective SHRM practices to motivate and retain them to improve the performance of banks (Abewickrama, 2016; Dwomoh and Frempong, 2017; Shahid, 2017), suggesting the importance of the mediating role of employee retention. However, there is a drought of literature on how the SHRM practices are operationalised across the management hierarchy and achievement of organisational performance through clear, consistent and relevant SHRM practices. The available studies tend to focus on upper level employees only when junior and supervisory employees have higher tendency to leave (Mbugua, Waiganjo and Njeru, 2014).

Moreover, nearly without prohibition, SHRM research has trusted on sign from private area associations and public area associations in disconnection. There is an expanding require the need to address this unevenness by thinking about a bunch of extensive SHRM practices as banks in both the sectors have their specific objectives to be achieved, however performance is defined (Knies, Boselie, Gould- 
Williams and Vandanabeele, 2018; Ongaro and Van Thiel, 2017), more so in the context of Sri Lanka which is developing rapidly after the war.

The expectation of this investigation is to choose whether SHRM rehearses are essentially connected with the exhibition of the banks, and whether representative maintenance intervenes the connection between the SHRM practices and execution of both the freely and exclusive banks in Sri Lanka. The Central Bank of Sri Lanka (CBSL) revealed that the financial business in Sri Lanka involves 25 authorized business banks, which incorporates 13 homegrown banks and 12 unfamiliar banks, two of which are neighborhood public banks (CBSL Annual Report, 2017). Information were gathered from representatives working in these banks in the Western territory of the nation, where a large portion of the branches are found. The information was then dissected utilizing auxiliary condition displaying (SEM). By tending to the previously mentioned holes, it is trusted that the investigation makes steady commitments to the group of information. From the handy viewpoint, it is trusted that the discoveries could fill in as a kind of perspective on what are the SHRM rehearses that the banks should focus on to hold their workers and to expand their presentation. The outcomes could likewise be utilized as a kind of perspective for financial specialists and strategy producers to settle on relative venture and strategy choices.

The following area presents the relevant writing, brought about the advancement of a consideration structure and a progression of theories to be tried. The technique and structure received in this investigation is introduced straightaway. This is trailed by the introduction of the key outcomes, alongside conversation on both their hypothetical and logical consequences. The paper is determined with limitations and future study directions.

\section{LITERATURE REVIEW}

\section{SHRM practices}

The asset-based view (RBV) hypothesis conditions that a firm develops upper hand by acquiring as well as arising, joining together and adequately masterminding its physical, human, and authoritative assets in manners that add extraordinary worth and are hard for contenders to impersonate.
The focal beliefs of RBV as proposed by different specialists (for example; Newbert, 2008; Wright et al., 2001) are that assets that are important, uncommon, supreme, and non-substitutable will prompt upper hand. Incentive in this sense is unmistakable from the utilization of assets either by abuse of motivators or by checking dangers to the association, while shortage is depicted as an asset that isn't right now open to an enormous number of later or expected adversaries of the association. (Barney, 1991).

The open doors supporting RBV can be utilized to more readily perceive SHRM techniques and practices. Regardless of whether ranking directors receive the best practice, possibility or key root of SHRM, they will attempt to get any esteemed HR they notice as being utilized by candidates as a wellspring of upper hand for their association. On the off chance that the resources can't be gained, directors will endeavor to recap the assets or locate an exaggerated that gives a tantamount bit of leeway. In the event that assets are quick to SHRM, supervisors will zero in on those important ones that contenders will think that its troublesome or difficult to impersonate for which no extra is essentially accessible. For ranking directors who like the commitments of vital origination of SHRM, more noteworthy pressure is put on distinguishing and developing inward human capitals as a wellspring of upper hand through the packaging of SHRM rehearses.

Bowen and Ostroff (2004) present the develop of 'solidarity of the SHRM' and depict the primary highlights of SHRM rehearses that bring about a solid hierarchical atmosphere where people share the regular explanation of what practices that are unsurprising and compensated. Among the numerous speculations, the AMO (capacity inspiration opportunity) hypothesis is seen to be at the center of SHRM that is chosen to decidedly shape optional practices of representatives (Boxall and Purcell, 2003; Lepak et al., 2006; Katou, 2008). The hypothesis clarifies the heap of SHRM rehearses dependent on three SHRM factors of: (1) capacity upgrade rehearses; (2) inspiration improvement practices; and (3) open door improvement rehearses. TABLE 1 sums up the 17 works on speaking to the three SHRM factors.

TABLE 1: SHRM Practices according to the AMO Theory

\begin{tabular}{|c|c|c|}
\hline No. & AMO Theory & $\begin{array}{r}\text { SHRM Practices } \\
\end{array}$ \\
\hline 1. & Ability enhancement practices & $\begin{array}{ll}\text { 1. } & \text { Recruitment and selection } \\
\text { 2. } & \text { Training and development } \\
\text { 3. } & \text { Work design } \\
\text { 4. } & \text { Performance appraisal }\end{array}$ \\
\hline 2. & Motivation enhancement practices & $\begin{array}{ll}\text { 5. } & \text { Compensation and benefits } \\
\text { 6. Promotion } \\
\text { 7. Encouragement } \\
\text { 8. Grievances } \\
\text { 9. Job confirmation } \\
\text { 10. } \\
\text { Communication }\end{array}$ \\
\hline
\end{tabular}

11. Participation in management

12. High performance

13. High commitment

14. Facilitating teamwork

3. Opportunity enhancement practices

15. Communications and involvement

16. Enhancing quality

17. Developing talent to serve the business in the future. 


\section{Employee retention}

Representative maintenance is a methodology by which employees are urged to proceed inside the association for the extraordinary timeframe. Worker maintenance is significant for associations just as representatives. In the event that workers feel disheartened with the current manager or the work, they will switch over to the following position. It is subsequently the duty of the business to hold their most noteworthy and top capable labor forces (Nor, 2018).

Worker maintenance conduct as a significant characteristic of SHRM rehearses has been perceived as a critical variable in the investigation of HRM (Katou and Budhva, 2008) in clarifying the association between SHRM rehearses and authoritative execution. As needs be, viable SHRM practices can lessen representative turnover and improve maintenance, prompting better authoritative execution, in this manner adds to tending to the 'black box' in the SHRMexecution affiliation. Nonetheless, the contention is dependent upon the setting by which the SHRM rehearses are viewed as significant and esteemed by the workers. A HR framework that fits the local traditions, authoritative or social foundations about the functions of supervisors and their associations with representatives, just as the mentalities of representatives themselves toward their work and lives will oversee which SHRM rehearses are probably going to be employable. An assessment of which SHRM practices can bring about worker maintenance is basic in order to assist manages an account with deciding (Zhang, 2005).

\section{Bank performance}

In this work study, bank performance is operationalized grounded on: (1) customer satisfaction of the bank; (2) service innovation; (3) quality of service; (4) operational efficiency; (5) level of productivity; and 6) profitability based on the measures developed by Katou (2008)

\section{SHRM practices and bank performance}

According to Dharmasiri (2016), effective human resources professionals can help the collective SHRM practices to reach the tipping point of their high impact on business performance by focusing on few but centrally important SHRM practices. This proposes that the recognizable proof of the significant segments of SHRM rehearses for hierarchical execution would assist with bettering hypothesize the nature and effect of SHRMexecution relationship.

\section{SHRM practices and employee retention}

From the possibility point of view, the writing recommends that the arrangement of SHRM practices of an association will be powerful on the off chance that it is steady with its maintenance methodologies (Aldamoe, Yazam and Ahmid, 2012). With the acknowledgement that profits and goodwill are generated through employees who are the backbone of the banks, investment in SHRM practices such as recruitment, induction, orientation, socialisation, training and development can minimise the turnover rate, as well as the cost of selection and recruitment.

\section{Employee retention and bank performance}

Employee retention has proven to be one key challenge for the banking sector in Sri Lanka to achieve its business objectives. From the contingency perspective, many scholars have argued that SHRM practices followed by retention strategies can determine organisational performance (Aldamoe, Yazam and Ahmid, 2012).

\section{Employee retention as a mediator between SHRM practices and bank performance}

The temporary linkages and cycles, through which SHRM rehearses influence authoritative execution, have gone up against scientists to characterize and look at their reasoning that opens the 'black box' between SHRM rehearses and hierarchical execution (Chuang and Liao, 2010). This in possibility hints to authoritative execution at the aggregate level. As indicated by their contention, the commitment of SHRM practices to authoritative execution is resolved by the decision of SHRM as well as by highlights and the synergistic impacts of the SHRM rehearses. Since there is no agreement or reliable proof outlining what comprises these HRM frameworks or packs that are related with high firm execution, the HR division needs to make SHRM rehearses that are seen as unmistakable, steady and express by representatives. In the event that SHRM rehearses have these highlights, it will make a solid SHRM which encourages the solid connections between worker maintenance and individual execution, which at last adds to better hierarchical execution.

\section{Research hypotheses}

From the aforementioned literature, it can be observed that previous study focusing on the association among SHRM practices and organisational performance can be grouped into two categories: (1) research on the direct association among SHRM practices and firm performance (Osterman, 1994); and (2) research on the internal mechanisms (i.e. mediators) through which the relationship between SHRM and organisational performance takes place (Batt, 2002). This study adopts the two categories, in which research of such a nature is still relatively limited (Nishii, Lepak and Schneider, 2007), including the context of the developing world. The following hypotheses were developed to be tested:

H1: SHRM practices significantly impact on organisational performance in the banking sector in Sri Lanka.

H2: SHRM practices are significantly associated with employee retention in the banking sector in Sri Lanka.

H3: Employee retention significantly impacts on performance of the banking sector in Sri Lanka.

In addition, this study includes the fourth hypothesis with employee retention as the mediator between the SHRM practices and organisational performance, depending on the statistical results of the first three hypotheses:

H4: Employee retention significantly moderates the relationship between the SHRM practices and performance of the banking sector in Sri Lanka.

\section{METHODOLOGY}

Sample

According to Lanka Business Online

(www.lankabusinessonline.com), the banking industry is densely concentrated in the Western province of Sri Lanka, with approximately $40 \%$ of the branches of licensed commercial banks located in this area. In addition, in terms of banking density (the number of bank branches per 100,000 individuals), it stands at 11.9 in the Western province against a range of 5.3 to 8.4 in other provinces, making this province an appropriate setting for the study to be conducted.

A total of 390 questionnaires were distributed to junior executives, managers and senior managers positioned in the branches of the licensed commercial banks in the Western province using the stratified sampling method. With 342 questionnaires returned, only 328 were found to be valid, yielding a response rate of $85.5 \%$. As shown in TABLE 2, the majority of respondents were female aged of 
31 and older. Their age corresponded with their years of experience, where the majority of them have worked for five or more years in their respective banks. Most of them hoped to remain working in the same bank for 15 or more years, followed by those between 11 and 15 years.
Many of them are executives, followed by managers and junior executives, with only one response from a branch manager responsible for human resources functions. In addition to the data reported in TABLE 2, 55.9\% of them are working for privately-owned banks, with the remaining with publicly-owned banks.

TABLE 2: Demographic Profiles of Respondents

\begin{tabular}{lccc}
\hline \multicolumn{1}{c}{ Age } & Percent & Experience & Percent \\
\hline $21-25$ & 4 & Less than 5 years & 9 \\
$26-30$ & 9 & $5-10$ years & 26 \\
$31-35$ & 27 & $11-15$ years & 20 \\
$36-40$ & 21 & 15 years or more & 45 \\
$41-45$ & 14 & & 16 \\
$46-50$ & 11 & Hope to Remain & 26 \\
50 and above & 14 & Less than 5 years & 17 \\
$\quad$ & $5-10$ years & 41 \\
Gale & & $11-15$ years & \\
Female & 49 & 15 years or more & \\
$\quad 51$ & & 3 \\
$\quad$ Designation & & & 1 \\
HR Managers & & & 10 \\
Branch managers responsible for HR functions & & 24 \\
Non-managerial employees & & 36 \\
Chief Managers & & 18 \\
Managers & & & \\
Executives & & & \\
Junior Executives & & & \\
\hline
\end{tabular}

\section{Questionnaire}

The reliability of the measurement tool was checked by maintaining quality and integrity of the criteria (Sekaran, 1992). In order to certify the integrity of the results, the survey instrument was pre-tested on employees from three banks in the field. The representatives of these banks have thoroughly reviewed the instrument and have offered suggestions for improving its wording and design. The final draft of the questionnaire was improved by using data on the pre-test Information from the pre-test survey.

The questionnaire constitutes four parts. The first part comprises questions on the demographic characteristics of respondents such as age, gender, years of working experience, how much longer they intend to work in the same bank and their designation. The second part of the questionnaire consists of items measuring SHRM practices, i.e. ability enhancement practices (13 items), motivation enhancement practices (15 items) and opportunity enhancement practices (14 items). The third part comprises six items measuring retention behaviour. The questions in the second and third part were scored using 5-point Likert scale of 1 (strongly disagree) to 5 (strongly agree). The fourth part of the questionnaire consists six items measuring organisational performance, scored on a 5 -point Likert scale of 1 (very poor) to 5 (very good).

\section{Data analysis methods}

The Statistical Package for Social Science (SPSS) and SEM using the AMOS version 23.0 software have been used to analysed collected data. This study used Factor analysis (FA) to further examine the measurement items used in this study. According to the Fidell (2007, p.26), FA is the best way to understand the underlying structure about particular theory and its variables in analysis. Two techniques of FA were usually used to discover the variables of interest from the set of coherent subsets that are relatively independent from each other, i.e. exploratory factor analysis (EFA) and confirmatory factor analysis (CFA) (Tabachnick and Fidell, 2007).

The SEM is a statistical procedure that takes a confirmatory (i.e., hypothesis-testing) approach to the analysis of a structural theory bearing on some phenomenon. It covers two important aspects: (a) the casual process represents series of structural equation; and (b) these relationships can be modelled pictorially. Following section explains the study result.

\section{RESULTS}

\section{Measurement model}

In this estimation model, the examination of the loads and t-estimations of developmental markers are appeared in Table 3. The outcomes demonstrated that the factors of SHRM practices and maintenance have high arrangement and huge reasonableness. As far as the SHRM practices, the outright qualities indicated that capacity improvement practices scored the most noteworthy weight, trailed by circumstance upgrade practices and inspiration improvement practices.

T-estimation can be utilized to decide likely appropriateness of factors to the pointer. Regarding the SHRM practices, all the three practices demonstrated 0.001 centrality, while for maintenance, the pace of representative turnover, goal of leaving the bank and accomplishing work that is imperative to workers indicated 0.001 of criticalness.

The 42 things speaking to the three first-request SHRM develops were dependent upon CFA as a necessary advance for testing the relationship of the show things with their particular idle builds (Hair et al., 2010). The outcomes demonstrated that all the qualities were inside the worthy reaches aside from the standard blunders. Furthermore, the examination was additionally directed with SHRM being estimated as a second-request build. 
The general Cronbach's alpha was 0.872, demonstrating a decent dependability.

The estimation model was tried in two phases. In the main stage, all estimation models were examined independently with the inert builds of capacity upgrade practices, inspiration improvement practices, opportunity improvement practices, representative maintenance and authoritative execution. In the subsequent stage, all estimation models were investigated as one model. In the event that the estimation model fit lists (GFI, AGFI, CFI TLI and RMSEA) are considered as not fit with the suggested values, at that point the estimation model would be reanalysed (Hair et al., 2010; Kline, 2005).

The fit records demonstrated a helpless fit (AGFI, GFI, CFI, TLI and GFI < 0.9; RMSEA > 0.08) in the underlying estimation model for the general structure.
The adjustment records demonstrated that the last model can be improved by permitting relationship of the things PE4 and PE5, PE6 and PE5, SHO9 and SH08, SHM10 and SHM9, SHM10 and SHM8, SHM7 and SHM5, SHM5 and SHM3, SHA11and SHA10, just as RT3 and RT2.

Since the consequences of factor examination indicated that the factor loads of the things were higher than 0.5 , the constant investigation of the attack of the general model basically assessed the extraordinary qualities showed by the adjustment records and exhibited the association way (co-fluctuation). The association ways satisfied fundamental prerequisite that the relapse bolts should be suffocate between mistakes associated with a similar factor (Gaskin, 2012) after the persistent dreary affirmation handled through the pertinent attack of the last generally speaking estimation model for the structure. The last estimation model fit lists are introduced in TABLE 3 where all fit lists accomplished the suggested levels.

TABLE 3: SEM Analysis of all Samples Model

\begin{tabular}{lcc}
\hline \multicolumn{1}{c}{ Fit indices } & Accepted value & Results \\
\hline Chi square/df & $<3$ & 2.049 \\
\hline & & \\
AGFI & $>0.9$ & 0.759 \\
GFI & $>0.9$ & 0.792 \\
CFI & $>0.9$ & 0.874 \\
TLI & $>0.9$ & 0.858 \\
RMSEA & $<0.08$ & 0.066 \\
P-value & $>0.000$ & 0.005 \\
\hline
\end{tabular}

The co-variances of the final measurement model are presented in TABLE 4. The assessment for unidimensionality of the final measurement model, as well as the further development of the final measurement model examining the co-variances of the final measurement model demonstrated that there were strong and positive relationships between employee retention and bank performance, as well as between
SHRM practices and employee retention and between SHRM practices and bank performance. All the co-variances in the final measurement model have high loadings (0.5) and are statistically significant $(\mathrm{p}<0.05)$. In the next stage, the model fitness checked by using all measurement models, as well as to address the issues with regard to validity and reliability.

TABLE 4: Co-Variances of the Final Measurement Model

\begin{tabular}{lllccccc}
\hline & & & Estimate & S.E. & C.R. & P & Correlation \\
\hline RT & $<-$ & PE & 0.320 & 0.051 & 5.957 & $* * *$ & 0.714 \\
SHRM & $->$ & & & & & $*$ \\
& $<-$ & PE & 0.271 & 0.046 & 5.958 & $* * *$ & 0.678 \\
SHRM & $->$ & & & & & $*$ \\
& $<-$ & RT & 0.314 & 0.059 & 5.522 & $* *$ & 0.718 \\
\hline
\end{tabular}

\section{Convergent validity}

Joined legitimacy alludes to the measure of shared distinction among things of similar builds. It likewise alludes to the measure of relationship among the things of a develop. Merged legitimacy of the build can be evaluated utilizing normal change extricated (AVE), thing loadings and composite reliabilities of the develop. The AVE is the level of variety clarified by the things in a build. The edge estimation of AVE is above 0.50 .
Since the estimations of AVE for all the builds were more than 0.50 (Table 5), all the develops have sufficient concurrent legitimacy. Likewise, the edge estimation of the composite unwavering quality should be above 0.70 (Gaskin, 2012). Table 5 likewise shows that all the develops have adequate unwavering quality, going from 0.810 to 0.961 . In this way, the current examination doesn't disregard the focalized legitimacy of the builds.

TABLE 5: Results of Convergent Validity Analysis

\begin{tabular}{ccc}
\hline Constructs & AVE & CR \\
\hline SHRM & 0.943 & 0.711 \\
Employee retention & 0.810 & 0.760 \\
Organisational performance & 0.961 & 0.762 \\
\hline
\end{tabular}




\section{Discriminant validity}

TABLE 6 shows the squared inter-construct correlation of each variable. The results showed that all of the constructs have satisfactory discriminant validity as the square root of average variance removed was greater than the inter-construct correlation of each variable and that the values of inter-construct were less than 0.85 .

TABLE 6: Results of Discriminant Validity Analysis

\begin{tabular}{llll}
\hline \multicolumn{1}{c}{ Construct } & SHRM & RT & PE \\
\hline SHRM & $\mathbf{0 . 8 4 3}$ & & \\
Employee retention & 0.823 & $\mathbf{0 . 7 0 7}$ & 0.838 \\
Organisational performance & 0.664 & $\mathbf{0 . 8 4 2}$ \\
\hline
\end{tabular}

\section{Hypotheses testing}

The final estimated model is presented in FIGURE 1. It indicates that the results showed a significant model fit [chi-square for this model was $\chi 2=294.121, \mathrm{df}=177$, CMIN/DF=1.662 (it must be $<3$ ), RMR $=0.050$ (it must be near to 0 ),
$\mathrm{GFI}=0.901$ (less than 1 shows a good fit), AGFI $=0.871$ (close to 1 shows a perfect fit), TLI $=0.933$ (near to 1 ), CFI $=0.944$ (near to 1 to show a perfect fit) and RMSEA = 0.053]. Thus, all the fitness statistics indicated an excellent fit to the overall model.

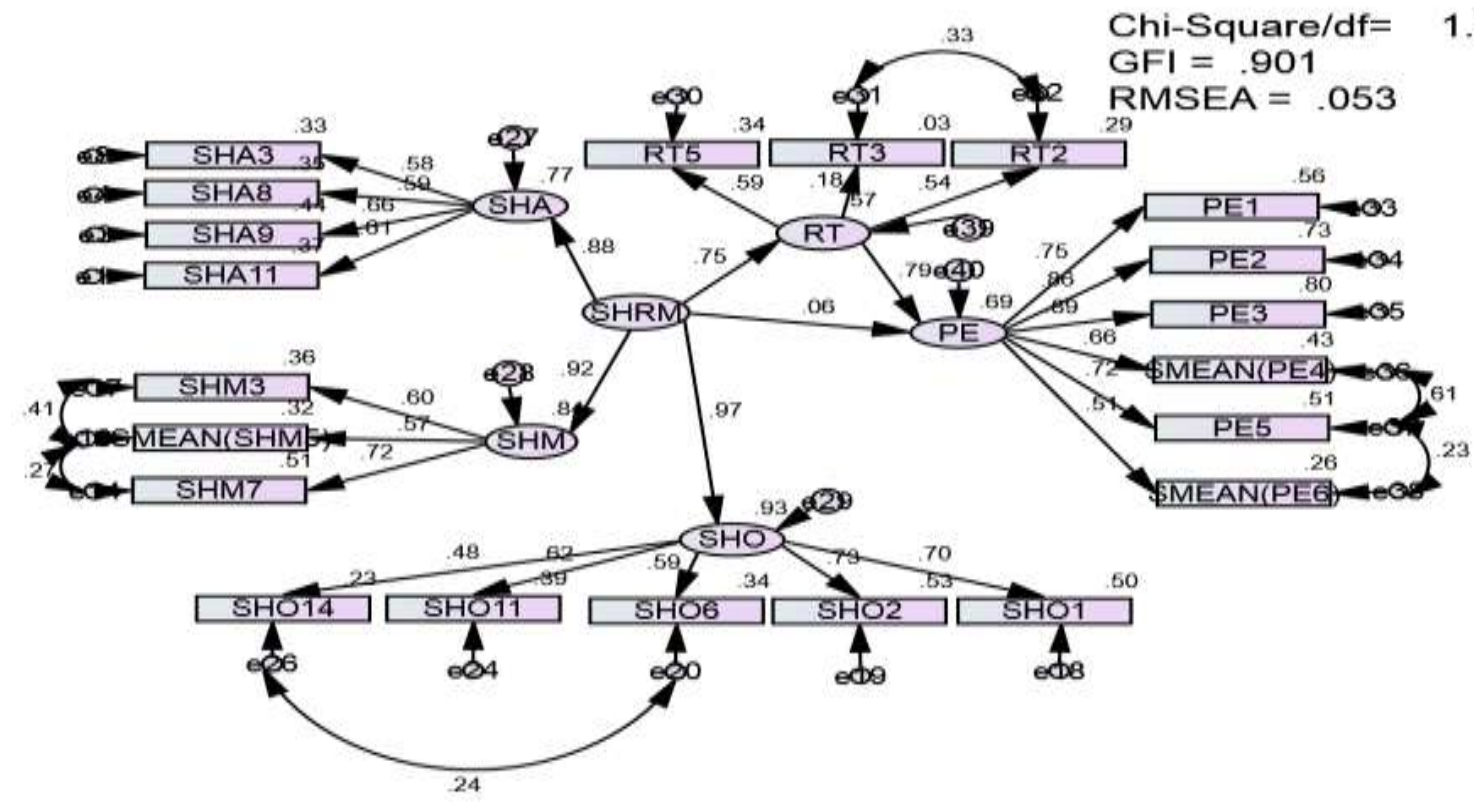

FIGURE 1: Results of Structural Equation Modelling

However, the results show that the organisational performance do not directly influenced by the SHRM practices significantly. But The ability enhancement practices, motivation enhancement practices and opportunity enhancement practices indirectly influence the performance of banks. The relationship between SHRM and performance of the organization is not direct but indirect.

The comparative effect (standardised regression weights) between the independent and dependent variables, i.e. SHM $\rightarrow$ SHRM $[0.965$ (9\%)], SHO $\rightarrow$ SHRM [0.875 (87\%)] and SHA $\rightarrow$ SHRM $[0.860(86 \%)]$, showed that the motivation enhancement practices are the strongest, followed by the opportunity enhancement practices and ability enhancement practices.

The first hypothesis states that SHRM practices significantly effect on performance of the organisation of the banking sector in Sri Lanka.
TABLE 7 shows that the path of SHRM $\rightarrow$ organisational performance has a p-value of 0.810 , which was more than 0.05 . Thus, H1 was not accepted. SHRM practices have non-significant impact on the performance of banks.

The second hypothesis indicates that SHRM practices are significantly associated with employee retention behaviour in the banking sector in Sri Lanka. As shown in Table 7, the path coefficient of SHRM practices and employee retention in the proposed final model is positive and significant $(\beta=.827, \mathrm{p}<.05)$. Thus, $\mathrm{H} 2$ is supported by the data.

The third hypothesis states that employee retention behaviour significantly impacts on organisational performance of the banking sector in Sri Lanka. Table 7 shows that the path retention $\rightarrow$ performance showed a pvalue of 0.010 , which was less than 0.05 . hence, H3 was accepted. Employee retention behaviour significantly impacts on bank performance. 
TABLE 7: Results of Hypothesis Testing

\begin{tabular}{|c|c|c|c|c|c|c|c|}
\hline & & & Estimate & S.E. & C.R. & $\mathbf{P}$ & Label \\
\hline RT & $<---$ & SHRM & .692 & .121 & 5.728 & $* * *$ & Significant \\
\hline PE & $<---$ & SHRM & .055 & .227 & .241 & .810 & Not significant \\
\hline $\mathrm{PE}$ & $<--$ & RT & .813 & .316 & 2.574 & .010 & Significant \\
\hline
\end{tabular}

The fourth assumption expresses that representative maintenance essentially directs the connection between the SHRM practices and execution of the financial area in Sri Lanka. In deciphering the examination, worker maintenance was impacted by SHRM works on, giving a positive high normalization coefficient however a low normalized coefficient on bank execution. The needy variable of the auxiliary model (direct impact), SHRM (way coefficient $=0.06$ ) and maintenance (way coefficient $=$ 0.79) were stacked onto the authoritative execution factor. The worker maintenance pointer (direct impact) and SHRM (way coefficient $=0.75$ ) was stacked onto the representative maintenance factor. Then again, the roundabout impact of autonomous variable through representative maintenance (0.59) was stacked onto the hierarchical execution factor.
TABLE 8 shows the examinations among immediate and circuitous impacts and the proportion impacts. At the point when the circuitous impact with the immediate impact were analyzed, the maintenance figure was high the immediate impact yet the SHRM variable demonstrated a high backhanded impact. In any case, after normalization of the immediate impact and circuitous impact coefficients, the proportion among the normalization union impact was up to $90.8 \%$. Since there is a distinction when the proportion is around $90 \%$ (Atsuko and Muta, 2006), it tends to be suggested that the aberrant impact affected the authoritative execution work. Accordingly, H4 was acknowledged. Worker maintenance is a critical moderater in the connection between SHRM rehearses and hierarchical execution.

TABLE 8: Direct and Indirect Coefficients

\begin{tabular}{ccc}
\hline Standardised coefficients & SHRM & RT \\
\hline Direct effect & $.06(9.19 \%)$ & $\mathbf{. 7 9 ( 5 7 . 1 4 \% )}$ \\
Indirect effect & $\mathbf{. 5 9 2 5 ( 9 0 . 8 \% )}$ & $.5925(42.85 \%)$ \\
Total effect & $.6525(100 \%)$ & $1.3825(100 \%)$ \\
\hline
\end{tabular}

Bold font indicates high values of standardization coefficients.

\section{DISCUSSION AND IMPLICATIONS}

\begin{tabular}{lccc}
\hline & Variable & Weights & t-value \\
\hline SHRM & SHA & .982 & 7.588 \\
& SHO & .908 & 7.922 \\
& SHM & .815 & 1.00 \\
RT & & & \\
& RT1 & .572 & 6.403 \\
& RT2 & .150 & 2.043 \\
PE & RT3 & .588 & 1.005 \\
& PE1 & .750 & 1.000 \\
& PE2 & .855 & 13.428 \\
& PE3 & .894 & 14.010 \\
& PE4 & .660 & 14.000 \\
\end{tabular}

\section{Research implications}

The hypothetical model developed for this study has provided a good understanding of the cause and effect relationships between the determinants (SHRM practices), employee retention and performance of banks by reducing the common-measure bias problem found in the study of Lipe and Salterio (2000). The model advocates that SHRM practices directly and positively influenced the retention behaviour of employees, which directly and positively influenced organisational performance. The SHRM practices have also been found to indirectly influenced organisational performance in a significant and positive direction.

The model agrees with Gardner, Moyniham, Park and Wright (2001) and Purcell and Hutchinson (2007) contend that in the HRM-execution causal chain, it isn't HRM results that influence hierarchical execution, yet may exist a sequential causation from representative conduct, for example, maintenance which at last influences authoritative execution.
In this way, to improve authoritative execution, the degrees of maintenance conduct should be improved by presenting the SHRM works on utilizing capacity upgrade, for example explicit preparing for representatives in the bank and changed the manner in which their work is finished.

\section{Practical implications}

The findings provide significant practical implications not only for branch (business unit) managers within banking sector, but also to all of the decision-makers involved in the formulation and implementation of SHRM strategies and practices. Realising that retention strategies and SHRM practices are not mutually independent, banks should develop and continue effective SHRM practices with respect to the retention strategies they follow. To achieve this, banks should have HRM departments and representation of these departments at the board level (Paauwe and Richardson, 1997). 


\section{CONCLUSION AND FUTURE RESEARCH DIRECTIONS}

The examination has made some significant commitments. It tests hypothetical presumptions with regards to a creating economy and offers help for the viewpoint that aberrant connection between SHRM practices and hierarchical execution exists, particularly with representative maintenance going about as an arbiter.

In any case, the above suppositions should be seen with alert. There are disadvantages related with the type of the study poll. While care has been taken to that the restriction of the cycle, potential reaction predispositions that actually exist. This investigation was performed distinctly on business banks in Sri Lanka. The investigation suggests that comparative examinations should be done in different areas of the economy on the impact of SHRM rehearses on authoritative execution with intervening of representative maintenance. Also, the examination zeroed in just on how SHRM rehearses impact the exhibition of banks through the intervening impact of representative maintenance. Further investigations ought to likewise think about the directing impacts of business systems (cost, development and quality) which may yield fascinating outcomes.

\section{REFERENCES}

[1] Abdulkadir, D. S. (2012). 'Strategic human resource management and organisational performance in the Nigerian insurance industry: The impact of organisational climate', Business Intelligence, Vol.5, No.1.

[2] Aldamoe, F. M., Yazam, M., \& Ahmid, K. B. (2012). The mediating effect of HRM outcomes (employee retention) on the relationship between HRM practices and organisational performance. International Journal of Human Resource Studies, Vol. 2, No. 1, 75. doi:10.5296/ijhrs. v2i1.1252

[3] Ali Kadhim, A. (2017) Relationship between SHRM and Organizational Performance among Iraqi Oil Companies. J Glob Econ 5: 241.

[4] Appelbaum, E., Bailey, T., Berg, P. and Kalleberg, A. (2000). Manufacturing Competitive Advantage: The Effects of High-Performance Work Systems on Plant Performance and Company Outcomes, New York: Cornell UN Press.

[5] Arulrajah,A.A. and Anuja,A. (2013)Team working practices and team orientation of Lankan journal of Human Resource Management, vol.4,No.1,pp.1-13.

[6] Aswathappa, K. (2008), Human Resource Management: Text and Cases, Delhi: Tata McGraw Hill Publishing Company Limited.

[7] Awan.A.G. and Sarwar,G.H. (2015).INTEGRATED ROLE OF HRIS \& SHRM (SHRIS) IN BANKING SECTOR OF PAKISTAN. Global Journal of Human Resource Management, Vol.3(N0.1), 45-65. doi:10.15417/1881

[8] Batt, R. (1999). Work organization, technology, and performance in customer service and sales. Industrial and Labor Relations Review, 52, 539-564.

[9] Becker, B. and Gerhart, B. (1996). 'The impact of human resource management on organisational performance: Progress and prospect', Academy of Management Journal, Vol. 39 No. 4, pp. 779-801.
[10] Bowen, D. and Ostroff, C. (2004). 'Understanding HRM-firm performance linkages: The role of the "strength" of the HRM system', Academy of Management Review, Vol. 29 No. 2, pp. 203-221.

[11] Boxall, P. and Purcell, J. (2003). Strategy and Human Resource Management, New York: Palgrave Macmillan.

[12] Boxall, P., \& Steeneveld, M. (1999). Human Resource Strategy and Competitive Advantage: A Longitudinal Study of Engineering Consultancies. Journal of Management Studies, 36(4), 443-463.

[13] Calo, T. J. (2008). 'Talent management in the era of the aging workforce: The critical role of knowledge transfer', Public Personnel Management, Vol. 37 No. 4, pp. 403-416.

[14] Campbell, J.P., McCloy, R.A., Oppler, S.H. and Sager, C.E. (1993) A Theory of Performance. In: Schmitt, N. and Borman, W.C., Eds., Personnel Selection in Organizations, Jossey-Bass, San Francisco, 3570.

[15] Cascio, W.F. (2003). Managing Human Resources: Productivity, Quality of Work, Life, Profits, NewYork: McGraw Hill Higher Education.

[16] Chang, W. A. and Huang, T. C. (2005). 'Relationship between strategic human resource management and firm performance', International Journal of Manpower, Vol. 26 No. 5, pp. 434-449.

[17] Cheung, L. Y. (2016). The Role Employee Motivation in the Relationship between Personality Traits and Employee Job Performance, (Unpublished master's thesis). Delft University of Technology.

[18] Clegg, B. (2000), Team Spirit: Instant Motivation, India: Vinod Vasishtha.

[19] Coff, R. W. (1997). Human Assets and Management Dilemmas: Coping with Hazards on the Road to Resource-Based Theory. The Academy of Management Review, 22(2), 374.

[20] Dele, A. O., Ezekiel, A. O. and Alani, L. F. (2015) Strategic human resource management and organisational climate in the Nigerian banking industry', American Journal Environmental Policy and Management, Vol. 1 No. 3, pp. 38-50.

[21] Delery, J. E. and Doty, D. H. (1996). 'Modes of theorising in strategic human resource management: Tests of universalistic, contingency, and configurational performance predictions', Academy of Management Journal, Vol. 39 No. 4, pp. 802-835.

[22] Dessler, G., Lloyd-Walker, B. and Griffiths, J. (2007). Human Resource Management, Frenchs Forest, N.S.W.: Pearson Education Australia.

[23] Drucker, P. (1954). The Practice of Management, New York: Harper.

[24] Dyer, J. (2005). Human Resource Management: Evolving Roles and Responsibilities, Washington D.C.: Bureau of National Affairs.

[25] Dyer, L. (1984). Studying Human Resource Strategy: An Approach and an Agenda. Industrial Relations, 23(2), 156-169. 
[26] Eisenhardt, K. M., \& Martin, J. A. (2000). Dynamic capabilities: What are they? Strategic Management Journal, 21(10-11), 1105-1121.

[27] Evans, W.R. and Davis, W.D. (2005) HighPerformance Work Systems and Organizational Performance: The Mediating Role of Internal Social Structure. Journal of Management, 31, 758-775.

[28] Fey, C. F., Bjo“rkman, I., \& Pavlovskaya, A. (2000). The effect of human resource management practices on firm performance in Russia. International Journal of Human Resource Management, 11 , 1-18.

[29] Garavan, T. N., \& Carbery, R. (2012). A review of international HRD: Incorporating a global HRD construct. European Journal of Training and Development, 36(2/3), 129-157. doi:10.1108/03090591211215579

[30] Gerhart, B. (2007). 'Horizontal and vertical fit in human resource systems', in C. Ostroff and T. A. Judge (Eds.), Perspectives on Organisational Fit, pp. 317-348, New York: Psychology Press.

[31] Guest, D. and Conway, N. (2004). Employee WellBeing and the Psychological Contract: A Report for the CIPD, London: Chartered Institute of Personnel and Development.

[32] Hackman, J. R. and Oldham, G. R. (1976). 'Motivation through the design of work: Test of theory', Organisational Behaviour and Human Performance, Vol. 16, No.2, pp. 250-279.

[33] Hansen, B. E. (1999). 'Threshold effects in nondynamic panels: Estimation, testing, and inference', Journal of Econometrics, Vol. 93 No. 2, pp. 345-368.

[34] Hoskisson, R. E., Hitt, M. A., Wan, W. P. and Yiu, D. (1999). 'Theory and research in strategic management: Swings of a pendulum', Strategic Management Journal, Vol. 25 No. 3, pp. 417-456.

[35] Huselid, M. A. (1995). 'The impact of human resource management practices on turnover, productivity, and corporate financial performance', Academy of Management Journal, Vol. 38, No.3, pp. 635-670.

[36] Huselid, M.A., Jackson, S.E. and Schuler, R.S. (1997). 'Technical and strategic human resource management effectiveness as determinants of firm performance', Academy of Management Journal, Vol. 40, No.1, pp. 171-188.

[37] In N. Schmitt, \& W. C. Borman (Eds.), Personnel Selection in Organizations: 35-70. San Francisco: Jossey- Bass.

[38] Kamoche, K. (1996). 'Strategic human resource management within a resource-capability view of the firm', Journal of Management Studies, Vol. 33 No. 2, pp. 213-233.

[39] Kanungo, R. N. (1982). 'Measurement of job and work involvement', Journal of Applied Psychology, Vol. 67 No. 3, pp. 341-349.

[40] Kleiman, L. S (1997). Human Resource Management, A Tool for Competitive Advantage, New York: West Publishing Company.
[41] Knies, E., Boselie, P., Gould-Williams, J., \& Vandenabeele, W. (2018). Strategic human resource management and public sector performance: Context matters. The International Journal of Human Resource Management, 1-13. doi:10.1080/09585192.2017.1407088

[42] Lazarova, M. and Tarique, I. (2005). 'Knowledge transfer upon repatriation', Journal of World Business, Vol. 40 No. 4, pp. 361-373.

[43] Legge, K. (2005). Human Resource Management Rhetoric and Realities, London: Palgrave Macmillan.

[44] Lepak, D. P., \& Shaw, J. D. (2008). Strategic HRM in North America: Looking to the future. The International Journal of Human Resource Management, 19(8), 1486-1499. doi:10.1080/09585190802200272

[45] Lepak, D.P., Liao, H., Chung, Y. and Harden, E.E. (2006). 'A conceptual review of human resource management systems in strategic human resource management research', Research in Personnel and Human Resources Management, Vol. 25, pp. 217 271.

[46] Lodahl, T.M. and Kejner, M.M. (1965). 'The definition and measurement of job involvement', Journal of Applied Psychology, Vol. 49, No.1, pp. 24-33.

[47] Mackey, K. and Johnson, G. (2000). The Strategic Management of Human Resources in New Zealand, Auckland: Irwin/McGrawHill.

[48] Madueke, C. V. (2017). Organizational Culture and Employee Retention of Selected Commercial Banks in Anambra State, Nigeria.Saudi Journal of Business and Management Studies, 244-252.

[49] Malik, V. (2015). Effective role of electronic human resource management in organisation's development', International Journal of Advanced Research, Vol. 3 No. 11, pp. 1558-1561.

[50] Nor, A. I. (2018). HOW TO KEEP TOP TALENTED EMPLOYEES ON BOARD: A REVIEW OF LITERATURE. Global Journal of Human Resource Management, Vol.06(No.02), 52-59. Retrieved July 4, 2018.

[51] Peccei, R. and Rosenthal, P. (2001). 'Delivering customer-oriented behaviour through empowerment: An empirical test of HRM assumptions', Journal of Management Studies, Vol. 38 No. 6, pp. 831-857.

[52] Rathnaweera, R. R. (2010). Do HRM Practices Impact Employee Satisfaction, Commitment or Retention? Empirical Studies of Sri Lankan Public Sector Banks, Unpublished Master's thesis, University of Agder.

[53] Richard, O. C. and Johnson, N. B. (2001). 'Strategic human resource management effectiveness and firm performance', International Journal of Human Resource Management, Vol. 12, No.2, pp. 299-310.

[54] Riipinen, M. (1997). 'The relationship between job involvement and well-being', The Journal of Psychology, Vol. 131 No. 1, pp. 81-89.

[55] Schuler, R. and Jackson S. (1987). 'Linking competitive strategies with human resources management practices', Academy of Management Executive, Vol. 9 No. 3, pp. 207-219 
[56] Seidu, Y. (2012). Human Resource Management and Organisational Performance: Evidence from the Retail Banking Sector, Doctoral dissertation, Aston university.

[57] Shaw, M.E. (1981), Group Dynamics: The Psychology of Small Group Behaviour, New York: McGraw-Hill.

[58] Tawhida Khatoon, Muhammad Ruhul Amin, Md. Moyazzem Hossain. Strategic Human Resource Management (SHRM) Practices and Its Effect on Financial Performance: Evidence from Some Selected Scheduled Private Commercial Banks in Bangladesh. International Journal of Economics, Finance and Management Sciences. Vol. 1, No. 3, 2013, pp. 151-158. doi: 10.11648/j.ijefm.20130103.14

[59] Silva, V. D., \& Gamage, A. S. (2016). A Case Study in Identifying Gaps and Developing a Common Code of Ethics for Commercial Banks in Sri Lanka. SSRN Electronic Journal. doi:10.2139/ssrn.2908804

[60] Starr, E., Ganco, M., \& Campbell, B. A. (2018). Strategic human capital management in the context of cross-industry and within-industry mobility frictions. Strategic Management Journal, 39(8), 2226-2254. doi:10.1002/smj.2906
[61] Venkat R. (2005). 'Transformational leadership and outcomes: Role of relationship duration', Leadership \& Organisation Development Journal, Vol. 26 No. 6, pp. 442-457.

[62] Wood, S. (1996). High commitment management and payment systems', Journal of Management Studies, Vol. 33 No. 1, pp. 53-77.

[63] Wright, P. M. and Snell, S. A. (2005). 'Partner or guardian? HRs challenge in balancing value and values', Human Resource Management, Vol. 44 No. 2, pp. 177-182.

[64] Wright, P. M., Dunford, B. B. and Snell, S. A. (2001). 'Human resources and the resource-based view of the firm', Journal of Management, Vol. 27 No. 6, p. 701-708.

[65] Wright, P. M., McMahan, G. C. and McWilliams, A. (1994). 'Human resources and sustained competitive advantage: A resource-based perspective', International Journal of Human Resource Management, Vol. 5 No. 2, p. 301-310.

[66] Younge, K. A., \& Marx, M. (2016). The value of employee retention:Evidence from a natural experiment. Journal of Economics and Management Strategy, 25(3), 652677. 